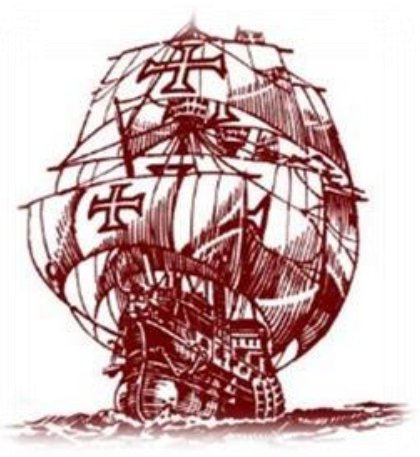

Nau Literária: crítica e teoria de literaturas

Www.seer.ufrgs.br/nauliteraria

ISSN 1981-4526 - PPG-LET-UFRGS - Porto Alegre

Vol. 11 N. $01-2015$

100 anos da geração Orpheu

\title{
Nas entrelinhas do desejo: uma carta
}

\author{
José Luiz Foureaux de Souza Júnior ${ }^{1}$
}

\begin{abstract}
Resumo: este trabalho tem como objetivo construir pontes para ligar as relações de amizade de dois poetas portugueses do final do século XIX: António Nobre e Alberto de Oliveira. O ponto de partida para a presente proposta é a leitura da correspondência de António Nobre (totalmente publicada). Nessa correspondência, aparecem indícios de que em cartas escritas por seu amigo, Alberto de Oliveira, havia laços estreitos até de amizade íntima que iam além do intercâmbio intelectual e literário entre ambos. Esta descoberta abre o caminho para uma abordagem para este jogo, sustentado pela perspectiva de "pacto homossocial", como apresentado por Eve Sedgwick Kosofski em seu livro Between men. Nesta perspectiva, a amizade entre os dois poetas, além de destacar os interesses poéticos e espirituais comuns, sugere uma relação estreita que leva a se cogitar com naturalidade a natureza afetiva da relação entre eles. Respeitados estes pressupostos, a leitura de uma das cartas de António Nobre a Alberto de Oliveira pode ser enriquecida por outras perspectivas que alargam o âmbito da crítica da literatura produzida por eles, especialmente quando se considera o contexto português do final do século XIX, a que essa relação se circunscreve. O trabalho se encaixa no âmbito alargado dos estudos de Literatura Comparada, sobretudo os circunscritos à Estética da Recepção, o que corresponde a análise e renovação de exercício crítico de releitura a partir de gêneros literários diversos, como a epistolografia, retomando criações literárias em perspectivas novas e renovando o alargamento constante de escritores representativos.
\end{abstract}

Palavras-chaves: Alberto de Oliveira; Leitura; Poesia; Homoerotismo; António Nobre.

Abstract: this work aims to build bridges to connect the friendly relations of two Portuguese poets of the late nineteenth century: António Nobre and Alberto de Oliveira. The starting point for this proposal is the reading of António Nobre correspondence (fully published). In this correspondence, appear evidence that in letters written by his friend, Alberto de Oliveira, close ties to the close friendship that goes beyond the intellectual and literary exchanges between them. This discovery opens the way for an approach to this game, supported by the perspective of the "homosocial pact" as presented by Eve Kosofsky Sedgwick in his book Between men. In this perspective, the friendship between the two poets, besides highlighting the poetic common interests and business spirittual, suggests a close relationship that leads to think naturally the affective nature of the relationship between them. Respected these assumptions, the reading of the letters of António Nobre to Alberto de Oliveira can be enriched by other perspectives that broaden the scope of review of the literature produced by them, especially when considering the Portuguese context of the late nineteenth century that this relationship is limited. The work fits into the broad scope of Literature Comparative studies, especially the circumscribed the Aesthetics of Reception, which corresponds to analysis and critical exercise of renewal rereading from various literary genres as epistolography, resuming literary creations on new perspectives and renewing the constant enlargement of representative writers.

Keywords: Alberto de Oliveira; Reading; Poetry; Homoeroticism; António Nobre

"Eu não queria falar na frente desse rapaz, que é muito agradável e faz o seu melhor. Mas eu não o considero suficientemente agressivo. Ele tem um rosto encantador, mas quando ele me chama de um bruto imundo ele poderia estar apenas repetindo uma lição." "Eu lhe

${ }^{1}$ Doutor em literature comparada pela UFMG, professor associado de liteteratura portuguesa e comparada na UFMG, realizando estágio pós-doutoral na Universidade de Coimbra. 
asseguro, ninguém disse uma palavra a ele", respondeu Jupien, sem perceber o quão improvável era esta declaração. "E, além disso, ele esteve envolvido no assassinato de um porteiro em La Villete." "Ah! isso é extremamente interessante", disse o barão com um sorriso. Marcel Proust, A la recherche du temps perdu, v. 6

Já disseram que a carta pode não ser considerada gênero literário. O questionamento que pode se apor a esta afirmativa gera uma série de reflexões que podem levar a uma série de alternativas. O fato é que a possibilidade existe e a liberdade de fazer uso desta mesma possibilidade também. Seguindo este rumo, tomo aqui a carta como gênero literário, sim; mais que isso, gênero poético. Há que se entender aqui o "poético" como conceito que identifica uma prática muito mais funda, densa e larga do que o literário. Este pode, etimologicamente, confundir-se em superficialidades outras. Pois então, a carta como gênero poético é expressão, penso eu, adequada para abordar as cartas que António Nobre escreveu para Alberto de Oliveira. Cabe finalizar esta abertura com a pergunta que faz Sophia Angelides: "Pode ser a carta lida e usufruída como obra de literatura, ou constitui apenas um material auxiliar para o conhecimento de seu autor, de problemas relacionados com a sua obra, de suas concepções e de seu ambiente social?" (ANGELIDES, 2001, p. 15)

De qualquer maneira, a questão está ligada ao cotidiano do pesquisador que se dedique ao gênero epistolar: como tratar o texto que tem em mãos? Onde encontrar o material concreto a pesquisar? Ou, então, pode-se perguntar, com Marie-Claire Grassi "Como estabelecer as normas da literariedade de uma carta?" Grassi postula que é possível pensar numa diferença entre cartas “ordinárias" e cartas "literárias". De fato, não há, de um lado, cartas reais, ordinárias e não literárias, e de outro, cartas fictícias e literárias. Cada tipo de carta, fictícia ou real, testemunha um certo grau de literariedade, quer dizer, certos traços que põem em relevo mais ou menos uma estética universal ${ }^{2}$. No entanto, permanece a dúvida: em que, exatamente, constituiriam esses "traços"? O que garantiria esse "certo grau de literariedade"? A própria Sophia Angelides parece ter uma boa resposta:

(...) embora numa carta a descrição de uma paisagem, o relato de um acontecimento, de uma vivência, a expressão de um sentimento, tenham o cunho da veracidade, da não-ficção, porque seu sujeito-de-enunciação é histórico, o material linguístico é submetido ao crivo altamente seletivo do escritor, que recria a sua experiência pessoal. (ANGELIDES, 2001, p. 17)

Ou seja, é possível sustentar a hipótese de que uma carta, por ser enunciação de um escritor, adquire a literariedade por passar pelo seu "crivo altamente seletivo". Mas somente

2 GRASSI, Marie-Claire. Lire l'épistolaire. Paris: Dunod, 1998, p.5. 
isso já é elemento suficiente para analisar a carta e reconhecê-la como literatura? É ainda Sophia Angelides que apresenta outro elemento para a análise: o destinatário. Segundo ela:

(...) sendo as cartas, em geral, dirigidas a uma determinada pessoa, esta orienta muitas vezes o grau de literariedade, de fragmentação, de espontaneidade, bem como o teor e o tom do discurso. [...] Entretanto, é preciso também considerar outros fatores decisivos no discurso epistolar, tais como o assunto, a situação em que o autor se encontra etc. Tudo isso conduz a forma do discurso e contribui para compor as suas múltiplas facetas, algumas de valor meramente documental, outras de valor estético ou estético-documental. " (ANGELIDES, 2001, p. 23.)

O conteúdo documental da carta de um escritor estaria submetido a duas mediações: uma, do próprio gênero epistolar, que seria a orientação do discurso conforme o destinatário a quem se dirige, e segundo o assunto, a situação em que o autor se encontra etc.; outra, decorrente de sua condição de escritor, que recriaria sua experiência pessoal conforme o seu crivo altamente seletivo a que estaria sujeito o material linguístico da carta. Esta situação genérica vai escapar de sua efetividade, quando da consideração da carta - quer seja gênero literário ou não, esta é uma questão subliminar aqui, necessária, é verdade, mas não a prioritária -, no contexto da correspondência entre António Nobre e Alberto de Oliveira.

Até onde é possível comprovar, apenas uma das cartas de António Nobre foi "respondida" por Alberto de Oliveira: a que marca o rompimento entre os dois. Confesso minha absoluta ignorância quanto aos "reais motivos" deste rompimento. No entanto, a julgar pelo teor da carta de Nobre, é possível inferir uma série de possibilidades que, aqui, por uma questão de espaço e escopo, não vêm ao caso. Mas a curiosidade fica aumentada. Isto é um fato. Na verdade, a ausência das cartas de Alberto de Oliveira faz com que o sentido de correspondência ganhe outros contornos. A atenção do leitor, para além dos elementos acima aventados, voltase para a imagem, o retrato, a figura desse poeta que aparece por meio desta mesma ausência. Como nas cantigas de amigo, em que a voz poética feminina sempre reclama da ausência do ser amado, fazendo-o absoluta e constantemente presente no entrecho dos poemas. Dá-se o mesmo nesta "correspondência".

De qualquer maneira, percebe-se a imanência da questão inicial aqui aventada: pode ser a carta lida e usufruída como obra de literatura ou constitui apenas um material auxiliar para o conhecimento de seu autor, de problemas relacionados com a sua obra, de suas concepções e de seu ambiente social? A resposta me parece um tanto óbvia. Assim não fosse, eu não me debruçaria na leitura destas cartas que gritam por respostas que, aparentemente, estão por vir, de algum lugar do passado. As cartas de António não apenas são documento de um processo criativo, poeticamente insinuado por sua própria escrita e pela publicação do Só, como também revelam a intimidade do poeta, igualmente exposta de maneira poética, ainda que matizada por 
sua característica melancolia e certo exagero. Nesta perspectiva, são esclarecedoras as palavras de Guilherme Castilho, editor de uma edição da correspondência de António Nobre:

O valor mais evidente deste conjunto de escritos pessoais vem-lhe precisamente de documentarem, de maneira sistemática e com um pormenor até hoje não revelado, como os vários lances da biografia do homem-António Nobre engendram a personalidade sui generis do artista criador - que o mesmo é dizer: como a sua sensibilidade, aqui multiplamente posta à prova em face da vida, foi determinante fundamental da formação do artista. Por isso é que ler estas cartas sem conhecer o Só seria ter a visão incompleta de uma unidade, conhecer uma causa que só verdadeiramente interessou pelo efeito que produziu. Revertendo à inversa - à hipótese de se ler o Só sem conhecer as cartas -,é evidente termos de reconhecer que a poesia daquele não precisará á estas para ter realidade, porque toda a obra de arte existe por si. Mas a «realidade» que ela é, a obra acabada que ela representa, tem no conhecimento e na interpretação destes documentos biográficos o mais precioso instrumento de estudo da evolução do «fazendo» para o «feito». (CASTILHO, 1982, p. 14) ${ }^{3}$

Percebe-se neste comentário a consonância com o questionamento que o antecede. Sem delongar muito nesta micro polêmica, acrescento apenas que o exercício dinâmico da leitura quer das cartas, quer do livro de António Nobre, quer ainda do trânsito entre ambos os conjuntos de textos - faz bem ao conhecimento do poeta. Na mesma medida, oferece a oportunidade para um melhor entendimento do processo criativo do mesmo poeta. Além disso, esse mesmo exercício abre a possibilidade de inferir detalhes e nuances na personalidade cartorial do homem António Nobre, sobretudo no que diz respeito à sua afetividade e a seus relacionamentos pessoais - incluindo-se aí, obviamente, a amizade íntima partilhada com Alberto de Oliveira. Ao fim e ao cabo, o que vale mesmo é a leitura dos textos - poesia e cartas - como forma de alargar o conhecimento em seu mais largo e denso conceito.

Para a proposta de leitura que aqui apresento, não transcrevo a carta que me interessa na íntegra, porque longa. No entanto, para que a análise não fique desarticulada e pareça solta ou, mesmo, sem sentido, transcrevo a passagem em que se encontram os elementos suficientes para sustentação de minha leitura, apesar de também não ser assim tão curta:

Uma nota curiosa desta manhã: um casal de passarinhos do tamanho de cotovias tem vindo a acompanhar o vapor, em pleno alto-mar, tão longe de terra; a esta hora não sei o que será deles, ou vão pisados no paquete, ou tombaram esfalfados sobre a água. Pobres Almas de Alice e Alberto! Sabes o que esta manhã vi, também, curiosíssimo? Uma baleia, mas distante infelizmente, notando-se apenas a água que o monstro espirrava para o Ar. Não me borrifou, entretanto. Também te quero dizer que o Britannia nasceu em 1873, tendo pois a tua idade: sois, talvez, gêmeos, mas não sois com certeza patrícios, por que o teu corpo de Purinho, desengonçado e cor de leite, foi batizado na concha de pedra da Igreja de Santo Ildefonso, o desse monstro do Britannia, sólido e negro, tem o seu nascimento arquivado, nalguma babilónica oficina de Liverpool. Contudo, há esta coincidência mas eu não consinto que a tua pilinhamorango, toque nem de leve o vergalho deste paquete. Alberto, são $2^{1 / 2}$ da tarde: vou à tolda saber notícias da nossa marcha e, pela noite, depois do jantar, virei concluir esta folha. Até logo. (CASTILHO, 1982, p. 116)

\footnotetext{
3 O trecho está em itálico no livro publicado por Guilherme de Castilho. Conservo aqui a formatação que lhe deu o editor.
} 
Uma pena não ter sido encontrada a carta que possivelmente Alberto de Oliveira teria escrito a António Nobre depois desta, ou mesmo, antes. Caso assim o fosse, poder-se-ia averiguar até que ponto a correspondência entre os afetos que enlaçavam os dois poetas verificase na "correspondência" que mantiveram durante tanto tempo. Sobretudo no que diz respeito às comparações que Nobre faz. A reação de Alberto seria por demais esclarecedora, mas vai ficar sepultada na campa das inferências.

De qualquer maneira, vale a sua abordagem, nos termos em que aqui se coloca. A carta em que se encontra este trecho foi escrita em 24 de outubro de $1890^{4}$, e foi enviada por António Nobre do navio Britannia, quando a caminho de Paris. Vale lembrar que o estado de espírito do poeta não era dos melhores. Por um lado, havia sido reprovado por duas vezes seguidas nos exames em Coimbra, não podendo conseguir aí o diploma de Bacharel em leis. Por outro, a separação do "amigo mais querido" que ficou em terras portuguesas, o que criou o horizonte de expectativas das cartas que trocaram. O poeta faz, neste passo da carta, uma comparação entre o navio em que viaja e o corpo de Alberto de Oliveira. Uma comparação não apenas "saborosa", mas reveladora.

O adjetivo destacado, remete-me a Barthes em seu livro $O$ prazer do texto. Como espaço de exposição da intimidade - ainda que este não seja, conscientemente, o objetivo de quem escreve - uma carta é sempre circunscrição de um perímetro desenhado pelo desejo, seja ele de que natureza for. De um modo ou de outro, a carta enseja uma experiência que tem "sabor", porque revela/constrói um "saber", simultaneamente, sobre quem escreve e sobre quem lê. Ambos degustam este processo e seu resultado, seus efeitos. Neste jogo de sedução mútua, via de mão dupla sustentada pelo texto, há o que Barthes chama de jouissance. Cito abaixo o trecho dele que interessa, incluindo a nota do tradutor brasileiro que, a meu ver, ajuda, e muito, na

\footnotetext{
$4 \quad$ Uma observação estranha. Na consulta que fiz na internete, encontrei referências a oito navios com o nome Britannia. Um deles naufragou em 1873, um outro foi demolido em 1909. Os demais são posteriores a este período. A considerar data da carta, cabe afirmar que se trata deste, no caso da viagem de Nobre. No entanto isso contradiz a base de toda a comparação que faz com Alberto de Oliveira, pois o primeiro aqui referido foi construído em 1863. Somente no caso do naufrágio, há coincidência entre as datas... Isso parece muito sintomático e sugestivo. Consultado em http://en.wikipedia.org/wiki/SS Britannia, no dia 5 de Fevereiro de 2015.

5 Coloco a expressão entre aspas, não porque alguém a tenha citado - e creio que tenha sido - mas porque é usada aqui e ali, e por mim mesmo, para identificar Alberto de Oliveira.(*) Alguns críticos têm considerado que a melhor tradução de jouissance para o português seria gozo, uma vez que esta palavra daria, de um modo mais explícito, o sentido do prazer físico contido no termo original. De nossa parte, acreditamos que a palavra fruição, embora algo mais delicada, encerra a mesma acepção - gozo, posse, usufruto" -, com a vantagem de reproduzir poeticamente o movimento fonético do original francês. Em todo caso fica para o leitor o prazer que pretenda desfrutar nesta leitura. J. G. (Os grifos são do próprio tradutor).
} 
compreensão da relação estabelecida entre os dois poetas portugueses, de que a carta em questão é instrumento de comunicação e partilha de afeto:

(Prazer/Fruição (*): terminologicamente isto ainda vacila, tropeço, confundo-me. De toda maneira, haverá sempre uma margem de indecisão; a distinção não será origem de classificações seguras, o paradigma rangerá, o sentido será precário, revogável, reversível, o discurso será incompleto.)

Se leio com prazer esta frase, esta história ou esta palavra, é porque foram escritas no prazer (este prazer não está em contradição com as queixas do escritor). Mas e o contrário? Escrever no prazer me assegura a mim, escritor o prazer de meu leitor? De modo algum. Esse leitor, é mister que eu o procure (que eu o drague), sem saber onde ele está. Um espaço de fruição fica então criado. Não é a pessoa do outro que me é necessária, é o espaço: a possibilidade de uma dialética do desejo, de uma imprevisão do desfrute: que os dados não estejam lançados, que haja um jogo. (BARTHES, 1973, p. 7-8)

A passagem de $O$ prazer do texto encerra o sentido que pretendo perceber e sustentar, na leitura da passagem da carta de António Nobre, referida acima. Nela, a decisão do tradutor de usar "fruição" no lugar de "gozo" faz com que eu, de certa forma, pense na experiência pela qual passou António Nobre enquanto escrevia esta carta. Percebe-se, claramente, a meu ver, o seu "prazer" ao falar do "amigo mais querido". Por outro lado, fica estabelecido um elo de significação entre os elementos utilizados pelo poeta na construção de sua comparação, sobretudo o morango, como há de se ver mais abaixo. De qualquer modo, as ideias de Barthes neste trecho sustentam a minha ideia de que a leitura das cartas a posteriori cria o espaço a que o autor francês se refere. O espaço da fruição/gozo que a leitura proporciona e que pode ser intensificado pelas associações livres que a partir do texto se constroem. Estas influenciam diretamente na mesma experiência de fruição/gozo da leitura, em continuum.

A passagem da carta aqui considerada está, de fato, diretamente ligada aos indícios da existência das cartas de Alberto de Oliveira, em resposta às que recebeu de António Nobre. Mais um deles... Para além disso, muito além aliás, está uma série de três pares comparativos feitas pelo poeta “da torre", envolvendo seu amigo e o navio em que viajava. Deste trecho, já destaco a seguinte passagem:

“... sois, talvez, gêmeos, mas não sois com certeza patrícios, por que o teu corpo de Purinho, desengonçado e cor de leite, foi batizado na concha de pedra da Igreja de Santo Ildefonso, o desse monstro do Britannia, sólido e negro, tem o seu nascimento arquivado, nalguma babilónica oficina de Liverpool. Contudo, há esta coincidência mas eu não consinto que a tua pilinhamorango, toque nem de leve o vergalho deste paquete. " (NOBRE apud CASTILHO, 1982, p. 116) 
O primeiro par, menos "saboroso", aponta para a coincidência entre o ano de nascimento de Alberto de Oliveira e o de inauguração do Britannia, $1873^{6}$. São "gêmeos", como diz Nobre, apesar de nacionalidades diferentes. Dada a particular oscilação de António Nobre em relação a seus sentimentos quando se trata dos ingleses, de cara, evidencia-se a preferência pela própria identidade cultural, o que vai ficar cada vez mais evidente nos pares comparativos seguintes.

De mais a mais, considere-se o que Guilherme de Castilho diz na "Introdução" ao volume que encerra a correspondência do poeta. Este "detalhe" aprofunda a hipótese defendida pelo editor da correspondência quando afirma que a leitura das cartas não prescinde da leitura do Só, e vice-versa ${ }^{7}$. Isto posto, a abordagem dos pares comparativos, como é feita aqui, segue o rastro do que propõe o editor das cartas. Por tabela, a fortuna crítica do poeta se enriquece e a contextualização, simultânea, de sua vida e de sua obra recebem o mesmo influxo de compreensão e alargamento crítico. Ao fim e ao cabo, o caráter homoafetivo da relação entre os dois poetas fica, ainda uma vez, confirmado e um tanto mais explícito.

$\mathrm{Na}$ primeira assertiva do segundo par comparativo, António Nobre opõe "o corpo de Purinho, desengonçado e cor de leite" a "monstro do Britannia, sólido e negro". Os adjetivos em contraposição explícita revelam dobras semânticas insuspeitadas, quando observados/lidos sob o enfoque da lente do homoerotismo: "desengonçado" opõe-se a "sólido", deixando entrever a delicadeza do afeto que aproxima e une os dois poetas, não sem confirmar a intimidade física entre eles. O sentido dicionarizado de "desengonçado", aqui, é abandonado para ceder espaço a uma acepção envolvida por afeto, carinho, que ressalta, ainda uma vez, a delicadeza da relação entre os dois poetas.

Na sequência, "cor de leite" opõe-se a "negro". O cromatismo, em primeira instância apela para a dicotomia totalidade/nulidade se se considerar o pressuposto da Física, que apresenta o branco como a presença de todas as cores e o negro como a sua ausência. Daí para o simbolismo de dicotomias que as duas cores ensejam e sustentam é um pulo: a pureza e a sujidade, a inocência e o vício, o dia e a noite, o permitido e o condenado.

Num breve excurso a esta argumentação, cabe destacar a brancura referida pelo poeta sem sua comparação. Isto porque, em outras alturas da correspondência, há referência ao leite como líquido de celebração da amizade afetuosa partilhada por António Nobre e Alberto de

6 Parece haver confusão aqui. A confiar no Google (http://en.wikipedia.org/wiki/SS Britannia), há oito referências a navios com este nome. Um deles naufragou em 1873. Nenhum dos outros tem qualquer relação com o ano de 1873. Terá sido ato falho do poeta? Gralha na edição das cartas? Como não tive acesso aos originais ademais este não é o meu principal objetivo com a pesquisa que está em curso - não poderei averiguar. Mas é instigante a constatação que faço apenas agora, quando da redação deste artigo.

$7 \quad$ Op. cit., p. 15. 
Oliveira: torna-se quase um ícone. Ora, se o caráter simbólico for aqui (também) viável, seria aceitável associar a substância do leite como elo que traz à tona o sêmen, muitas vezes identificado terminologicamente à mesma substância. Esta inferência coloca-se a anos luz de distância de qualquer insinuação de sodomia/pederastia, como variante (ainda que possível) do pacto homossocial estabelecido, mesmo que inconscientemente. No diapasão desta nota, a Psicanálise dá o tom, fazendo com que a plausibilidade da associação seja respaldada pelo axioma lacaniano que toma a linguagem como modo de operação do inconsciente.

A "insinuação" a que me refiro acima não tem aqui o papel de determinar o direcionamento dos sentidos que circunscrevo aos pares opositivos que examino. Estou longe, muito longe, de querer afirmar que as práticas de sodomia e/ou pederastia foram um dos aspectos da relação entre António Nobre e Alberto de Oliveira - que seria passível de punição, como bem lembra Ana Paula Arnaut em seu artigo aqui referido. Na verdade, a sustentar a hipótese que venho desenvolvendo, cabe muito mais argumentar a favor da supremacia do desejo. Assim, os pares comparativos funcionariam como uma espécie de jogo. Este, por sua vez, teria alguma semelhança ao que é pensado por Freud a este respeito.

Seguindo em frente, a segunda assertiva da mesma comparação aponta para outra dicotomia: sagrado/profano. A "concha de pedra de Santo Ildefonso" é o par opositivo de "nalguma babilónica oficina de Liverpool”. Ressalte-se que a referência utilizada por Nobre Alberto/Igreja de Santo Ildefonso e Britannia/Liverpool - também pode levar a outro nível de comparação, que é o das circunstâncias e da conjuntura da Europa à época. Por metonímia, é plausível pensar na comparação entre o desenvolvimento da Inglaterra e certo atraso industrial português.

Ora, a "concha de pedra" opõe-se à "babilónica oficina". A primeira recebe, aconchega, acolhe; a segunda produz, apresenta, lança. O adjetivo "babilónica" é o significante que dispara o discurso comparativo de oposição entre o sagrado e o profano. De mais a mais, a mesma oposição serve para reforçar o caráter afirmativo da valorização do relacionamento entre os dois poetas, conforme atestado nesta correspondência. Uma vez mais, por vias transversas, o pacto homossocial é celebrado.

Ao final, o terceiro par comparativo, o mais "saboroso", eu diria. Admitindo, uma vez mais, a coincidência, António Nobre nega consentimento à identificação completa entre o navio e o seu amigo: a "pilinha-morango" é oposta ao "vergalho". Pila, em Portugal, é usado para identificar o pênis, sobretudo coloquialmente. No Brasil, mais especificamente no Rio Grande 
do sul, significa, também, dinheiro ${ }^{8}$. O primeiro significado coloquial se aplica a "vergalho". O diminutivo do primeiro, que pode ser referência à dimensão do órgão masculino, aprofunda o sentimento carinhoso e delicado devotado pelo autor da carta a seu amigo.

A força fonética do segundo termo confirma a ideia representada pelo navio, nas comparações feitas por António Nobre. O "sabor" da comparação - e aqui o sentido do substantivo se sustenta no pensamento barthesiano - não deixa de ser sugestivo, no uso de "morango", funcionando como índice identificador, uma espécie de predicativo do sujeito. Por um lado, a delicadeza da fruta que se revela no adocicado e no líquido associados ao paladar e, por outro, a cor que identifica, indiretamente, a "adolescência" de Alberto de Oliveira. Estes detalhes ratificam, uma vez mais e definitivamente, a delicadeza percebida, devotada e celebrada na/pela relação entre os dois poetas.

Na sequência de comparações feitas por António Nobre, se Freud não estava errado, percebem-se indícios do que este chama de compulsão à repetição. O poeta sempre volta ao navio como elemento comparativo em relação ao corpo de Alberto de Oliveira. Este aparece, na repetição, como elemento de desejo do sujeito nostálgico que é António Nobre a bordo do navio, a caminho de Paris, sozinho. Ao mesmo tempo em que constrói as comparações, forçosamente, Nobre recorda a sua experiência afetiva com Alberto. Isso funciona como combustível para o processo desenvolvido ao longo da carta. De acordo com Freud:

O recordar, tal como era induzido pela hipnose, só podia dar a impressão de um experimento realizado em laboratório. O repetir, tal como é induzido no tratamento analítico, segundo a técnica mais recente, implica, por outro lado, evocar um fragmento da vida real; e, por essa razão, não pode ser sempre inócuo e irrepreensível. (FREUD, 1976, p. 195)

Na comparação feita por Freud, o método da hipnose ajudava o paciente a recordar de elementos que serão analisados durante o processo terapêutico. Esses elementos funcionam como estopim para a eclosão dos sintomas que, tratados terapeuticamente, colocam o sujeito em estado de "normalidade". Evidentemente, a troca de cartas entre os dois poetas portugueses não é exatamente um exemplo de processo terapêutico, mas um seu similar. Na mesma medida, a hipnose não entra nas cogitações de abordagem desta troca de cartas, mas a repetição constante das comparações feitas por António Nobre sim. De qualquer maneira, essa atitude de Nobre, abre espaço para a especulação que desenvolvo sumariamente aqui.

No intuito de fazer "real" o seu afeto, mesmo levando-se em consideração o caráter introvertido da personalidade de António Nobre - como aqui já aventado - o poeta usa a

\footnotetext{
8 Outro nível de aproximação semântico-discursiva é facilitado aqui: o da associação entre sexo e dinheiro, leia-se prostituição e, no caso específico, masculina. A perspectiva sociológica fica mais explícita e eficaz. Isto fica para outra oportunidade, mais uma vez, por decurso de espaço.
} 
repetição, inconscientemente, é claro, como forma de alcançar a realização de seu desejo: a proximidade com Alberto de Oliveira. A propósito da aproximação com a Psicanálise, através da menção e dos comentários ao texto de Freud aqui referido, trago um comentário de Ana Paula Arnaut, acerca de um livro de Mário Cláudio, Retrato de rapaz. Sobre o romance, nesta perspectiva, ela diz:

Baseando-se, por exemplo, no estudo psicanalítico de "A Virgem e o Menino com Santa Ana", e também no que Leonardo da Vinci escreve no Codex Atlanticus ${ }^{10}$, sobre a memória de ter sido atacado no berço pela cauda de uma ave de rapina, o criador da Psicanálise (re)desenha nas vestes da Virgem os contornos de um abutre e defende que na imagem é possível observar a manifestação de uma homossexualidade passiva.

Segundo Freud, na apreciação da designada "fantasia do abutre", não esquecendo que esta é ainda decomponível em elementos simbólicos relacionados com o nascimento ilegítimo do pintor, e não esquecendo também que na hieroglífica egípcia este signo representa a ideia de mãe (...) (ARNAUT, no prelo)

Ora, os comentários dizem respeito a um romance de Mário Cláudio, no entanto, a ideia que destaco pode ser articulada à leitura do trecho da carta de António Nobre, objeto de minhas especulações aqui. Trata-se do jogo do Fort-Da, metaforicamente representado pelo trabalho de desenhar o contorno do milhano, ou milhafre - ou qualquer que seja a ave -, no quadro de Da Vinci, para desenvolver a sua hipótese de homossexualidade passiva do pintor. Este detalhe me interessa, o do jogo. Ao fazer o que fez, Freud corrobora o que faço com o tirar e por referências semântico-discursivas nos termos com os quais António Nobre constrói suas comparações entre Aberto de Oliveira e o navio em que viaja.

Jurandir Freire Costa, em seu livro A ética e o espelho da cultura, faz uma espécie de balanço semântico-discursivo, para não dizer histórico-conceitual, da ideia de certo/errado, normal/anormal, aceitável/condenável. Sem especificar um termo, ele passeia por esse tipo de dicotomia que atravessa a cultura ocidental. O que ele faz, serve como anteparo às ideias que desenvolvo neste artigo. Por isso mesmo, trago aqui um pequeno atalho ao seu longo percurso de raciocínio.

Aponta ele que, já há muito tempo, notadamente em 1484, quando o papa Inocêncio VII publicou uma bula condenando a excomunhão, interdição e outras penas e castigos "sem apelação" para todos os indivíduos que se opusessem às atividades inquisitórias, Heinrich Kramer e James Sprenger, dois monges dominicanos alemães de reconhecida presença no contexto das ações e efeitos do Tribunal do Santo Ofício publicaram O martelo dasfeiticeiras,

\footnotetext{
9 Óleo sobre madeira, pintada em Milão entre 1508 e 1513 e hoje exposta no Museu do Louvre, em Paris. Ver http://pt.wikipedia.org/wiki/A Virgem_e o o Menino_com_Santa_Ana (consultado em 12 de maio de 2014).

10 Compilação de estudos escritos entre 1478-1519 (12 volumes que atualmente se encontram na Biblioteca Ambrosiana, em Milão).
} 
manual dedicado à prática da Inquisição de mulheres possuídas. Neste livro, encontra-se a afirmação de que era heresia não acreditar em feitiçaria, pois "as leis eclesiásticas demonstravam que negar a existência de bruxas era contrário ao sentido óbvio do Cânon" (KRAMER; SPRENGER, 1991, p. 53). Encontra-se também nele, como em bons manuais o “como fazer" para os procedimentos de identificação reconhecimento e punição das mulheres ${ }^{11}$ possuídas.

Jurandir continua dizendo que, quase cem anos depois, em 1570, o médico francês Jean Weir escrevia Da impostura dos diabos, tratado polêmico em que era afirmado que nem todas as mulheres que se comportavam como feiticeiras eram, de fato, possuídas. Algumas eram doentes, loucas, e por isso, antes de julgadas e mandadas à fogueira, deveriam ser examinadas pelos médicos, os únicos que, à altura, estavam habilitados a entender "diferenças, regras e causas de qualquer mal engendrado contra a ordem da natureza" (WIER, 1970, p. 6).

Dando um salto para o século XIX - que nos interessa de maneira particular, dado ser neste período que se localiza a correspondência entre os dois poetas portugueses, da qual extraio o trecho de uma carta sobre a qual venho tecendo meus comentários - afirma-se certa "crença cega" no demonismo por parte de Wier, oscilando o caráter de seu pensamento entre o teológico e o médico. Em 1970, ainda sobre o mesmo autor, Marc Lamesi pergunta: “O ‘Diabo' de Jean Wier, este 'diabo' que faz agir as feiticeiras e que provocou tanto escândalo, não seria o 'inconsciente', ‘a peste’ sobre a qual não paramos mais de falar?” (Idem, ibidem).

Há e sempre houve controvérsias. Pode-se ou não concordar ou discordar dos argumentos que nelas circulam. De qualquer maneira, é irrecorrível reconhecer que o fenômeno da feitiçaria é mais uma prova da superstição de "almas pré-científicas". No estado atual das ciências - ainda que seja esta expressão ambígua em seu caráter discursivo comportamental faz-se mister levar em conta que o progresso do conhecimento respalda a certeza de que o mal de que sofriam feiticeiras e inquisidores é a ignorância, o desconhecimento ou recalcamento da realidade sexual do inconsciente.

Talvez não seja ousado demais afirmar que hoje, neste saber "científico", está a chave do enigma de ontem. No entanto, ao se deparar com textos como os das cartas de António Nobre para Alberto de Oliveira e, dentre elas, a que aqui tomo como objeto de observação, essa afirmação ganha outros contornos. Coloca-se, em questão - como bem quer a Psicanálise - a ideia de que a verdade, envolta durante tanto tempo na ilusão pode, por fim ser revelada. Esta assertiva também sofre a síndrome da desconfiança.

11 Fico me perguntando: será que somente as mulheres eram (foram) vítimas de possessão? E os homens? Há de haver histórias e mais histórias que possam vir a documentar as possíveis respostas a esta pergunta. 
As bruxas podem ser iconizadas como efeito da crença em bruxaria. Sem a crença em bruxas, não haveria mulheres que sentissem, agissem, se reconhecessem e fossem reconhecidas como bruxas. Tampouco haveria religiosos, moralistas, médicos, etc., no controle das discussões acerca das causas do fenômeno, na busca do melhor caminho para a "cura" e, obviamente, o controle dessas "anomalias". Analogamente, é possível pensar que as crenças a respeito da sexualidade são apresentadas como fundadas em "fatos evidentes". Deste modo, desde o século XIX, a divisão natural dos sujeitos em "heterossexuais, bissexuais e homossexuais" passa a ser mais um elemento a constar de supostos "manuais" - ainda que apenas imaginadas, por vezes concretizados - de controle e "cura". Categorias de um saber que pode ser dominado.

Isso impõe à maioria das pessoas um dado imediato da consciência, como algo "intuitivo" e, portanto, como algo universalmente válido para todos os sujeitos em qualquer circunstância espaço-temporal. No entanto, com um pouco de imaginação, é possível conceber um caráter mais flexível para taxonomias tão fechadas. Fico pensando no grau de angústia que devia manifestar-se inconscientemente no espírito de António Nobre e de Alberto de Oliveira, ao trocarem confidências íntimas, dando vazão a um afeto que, dadas as circunstâncias, tinha necessariamente de ser recalcado, metaforizado. Acredito que o exercício poético de ambos é a demonstração mais evidente do processo de recalcamento imposto a ambos pelas circunstâncias do momento em que viveram. Talvez esta tenha sido a estratégia de Nobre. Coisa de que duvido, mas não posso deixar de admitir como plausível, até provável. O teor das cartas é suficientemente consistente para sustentar tal hipótese. De mais a mais, o esforço - até prova em contrário, plenamente satisfeito de Alberto de Oliveira - de exigir a incineração de seus papéis parece-me funcionar como corroboração da manifestação de tal ansiedade. Para dizer o mínimo. Percebo isso em declarações como a de Guilherme de Castilho, quando de uma visita a Alberto de Oliveira, pouco antes da morte deste. Diz Castilho:

Por essa altura estava eu coordenando elementos para um trabalho que mais tarde publiquei sobre António Nobre. A vista de documentos de tão grande valor para o estudo da personalidade do poeta, lamentei que estes se conservassem inéditos. Sobre os últimos disse-me tencionar aproveitá-los um dia, «se Deus lhe desse vida e saúde». Mas - acrescentou - eram documentos tão íntimos, o seu tom de tal forma confidencial que só os divulgaria em parte e com notas suas aclarando passagens de mais delicada interpretação, decifrando o que em muitos passos era quase linguagem cifrada, revivendo memórias e reconstituindo ambientes inteiramente delidos pelo tempo. (CASTILHO, 1982, p. 10) $)^{12}$

12 O itálico é do próprio Guilherme de Castilho. Conservo a formatação do texto conforme livro por ele publicado. 
Continuando, no caminho traçado por Jurandir Freire Costa, há que se reconhecer que as taxonomias, a cada passo da História, acabam por ser úteis. Por sua utilidade não se pode afirmar a sua veracidade absoluta. Em outras palavras, não se pode acreditar que, diacrônica ou sincronicamente, tais aferições são relativas. A seguir, a lição de pensadores como Freud, Wittgenstein, Foucault ou Richard Rorty, conclui-se que tais questões são equivocadas em relação a uma outra, esta sim, fundamental: qual o interesse ou valor moral de tais divisões? Em que e por que importa identificar moralmente os sujeitos com base em suas "inclinações sexuais"13? Por que tomar a classificação das pessoas, como acima referido, como imperativo atemporal da "razão científica" e não como conformação - mesmo ficcional, se se aceitar a hipótese da carta como um texto que "cabe" neste "gênero" - das experiências afetivas, eróticas e/ou sexuais, tão datada historicamente quanto qualquer outra? Por fim, que arranjo imaginário das sexualidades contribuiria para a construção de ideais de decência pública e autorrealização individual?

A meu ver, fora deste enfoque, toda discussão sobre a assim denominada "homossexualidade" fica rebaixada ao nível de um exercício acadêmico fútil ou transforma-se em artigo de liquidação no também assim chamado "mercado do sexo". Sob a égide de pensadores como os acima citados, não há como denegar a evidência de que o sujeito é um "ser" de linguagem. Nada, na subjetividade ou na sexualidade do sujeito, escapa ao modo como ele a perceber, sentir, descrever, definir ou avaliar moralmente o que ele "é". Ambas são realidades linguísticas; mais, discursivas.

Portanto, é equivocado pensar que exista coisa sexual objetiva que preexista à forma como é conhecida linguisticamente. A palavra não é aquilo que diz, falsa ou verdadeiramente, o que a suposta coisa sexual é em si. A sexualidade é aquilo que a palavra diz que ela é. Não se pode simplesmente acreditar que alguém "seja" heterossexual, bissexual ou homossexual porque pura coação de um vocabulário que leva os indivíduos a identificarem-se uns aos outros utilizando estes termos. Este vocabulário, entretanto, não surge do nada. Sendo assim, deixa de ser a representação da "verdade" sobre a sexualidade, ignorada pelo obscurantismo de todos os que sobre ela pensaram antes de chegar aqui.

A verdade, como quer Richard Rorty, é uma crença sobre a qual ainda não se encontraram razões para ser colocada em dúvida. Neste sentido, pode ser entendida como uma espécie de medida que é dada àquilo que se faz útil para quem dela se utiliza. Ou, se se quer, é o simples estado da conversação atual no qual os últimos termos do debate não necessitam de

13 As aspas aqui funcionam como chamada de atenção para o fato de que esta é uma questão polêmica que, por decurso de espaço, vou ser obrigado a deixar de lado, contando com a colaboração do leitor. 
argumentos suplementares para se afirmarem como uma crença plausível. Esta inferência final segue o raciocínio de Jurandir Freire Costa, mas uma vez. A verdade sexual é filha da moral burguesa oitocentista. Surgiu e estabilizou-se, não por força dos eternos decretos da razão científica, mas pela força das construções de caráter e índoles variados: institucionais, políticos, científicos, econômicos, etc. Estas mesmas construções que, no século anterior, disputavam a posse e a fabricação de um sujeito adequado às suas estratégias de reprodução, expansão e hegemonia culturais.

Cabe introduzir uma pequena digressão quando se pensa em António Nobre e Alberto de Oliveira como sujeitos da linguagem que são - ambos são poetas, para além de tudo. A amizade que entre eles se constrói, se desenvolve - e as cartas são prova incontestável disso e se acaba - ainda que o motivo "real" do rompimento não tenha vindo a público - é dada a conhecer através de cartas. Textos que materializam a linguagem, que a realizam. Desta forma, ambos estão também circunscritos ao funcionamento desta linguagem - a poética - para o exercício da expressão de seus afetos. Assim, a consideração das cartas como textos que podem ser alocados na categoria de gênero literário, passam a ser uma espécie de documento de época que revela a circunstância, o conjunto de operadores socioculturais que acaba não só por contaminar as relações subjetivas como, até, dominá-las e dirigi-las. Em outras palavras, o que desejo afirmar é que ambos estão circunscritos aos limites que a linguagem impõe ao sujeito, por um lado; por outro, o contexto de época que determina como esta imposição se dá. Daí, talvez, abre-se uma possibilidade um tanto mais larga para entender, por exemplo, o porquê da exigência de Alberto de Oliveira e, talvez, do rompimento da amizade com António Nobre, ao que parece, promovido por este.

Para encaminhar este raciocínio a uma conclusão, ainda que relativa, é preciso lembrar de que, uma vez criadas, as práticas morais e intelectuais tornam-se quase absolutas na demarcação do limite de possibilidades das identificações sexuais de cada indivíduo. A escolha entre preferências sexuais, assim como da língua materna, é algo que está no âmbito da impossibilidade. A sexualidade, acompanhando o pensamento de Freud, é, ao fim e ao cabo, contingente, arbitrária e casual, mas isto não quer dizer que seja gratuita. Existe a fronteira, o limite de um repertório sexual, da ordem da "cultura", até que novas práticas linguísticas produzam novos modos de identificação moral dos sujeitos.

O problema reside no fato de que este mesmo sujeito não consegue ser senhor em sua própria morada sexual. Paradoxalmente, instaura-se a liberdade - esta sim, subjetiva - para redescrever moralmente a versão imposta às formas de amar e desejar sexualmente. Ninguém pode escolher que tipo de desejo ou atração sexual será a sua, mas qualquer um pode aprender 
a definir o que sente conforme seus padrões éticos. Faço eco às palavras de Jurandir Freire Costa por acreditar, com ele, que continuar discutindo sobre "homossexualidade", tendo como pressuposto a ideia de que é possível nomear os indivíduos a partir da expressão de sua sexualidade - por impossível, de fato - significa subscrever, como cúmplice, a um jogo de linguagem que se mostrou violento, discriminador, preconceituoso e intolerante. Este jogo, diferentemente do Fort-Da freudiano, leva ao equívoco - para dizer o mínimo - de acreditar que pessoas comuns como qualquer um são "moralmente inferiores" só pelo fato de sentirem atração por outras do mesmo sexo biológico.

Mais uma breve interrupção para referir aqui a delicadeza da relação entre os poetas portugueses que não se pode dizer por razões óbvias. No entanto, ainda que a contrapartida de Alberto de Oliveira não se já mais possível de manipular, as cartas de António Nobre são a clara ilustração não só do recalcamento a que antes me referi, como também do jogo linguístico que menciono acima. Neste sentido, à parte toda e qualquer outra interpretação que do texto de Nobre possa vir a ser feita, é inegável a evidência de que, poeticamente, as cartas dão vazão a um desejo que encontrou outra forma para se expressar. Mesmo sendo cartas, o teor poético de sua linguagem pode ser lido como exercício estético de sublimação - em termos freudianos de um afeto que atormentava e impunha-se recalcar. Por outro lado, numa visada mais ampla, a relação que se descreve poeticamente nas cartas é o "documento" que chancela a existência e efetividade dos jogos de linguagem a que Jurandir Freire Costa se refere no eco de suas ideias que aqui trago.

O vocabulário a respeito da sexualidade e a tudo o que o campo semântico-discursivo desse termo enseja é viciado nas perguntas que faz e nas respostas que obtém. As conclusões a que se pode chegar, quando do seu emprego, estão todas postas quase como pressupostos. No fim da argumentação, chega-se à mesma conclusão (equivocada): homens e mulheres são, foram e serão sub specie aeternitatis "heterossexuais, bissexuais e homossexuais". A assertiva pode parecer indiscutível e suficiente para entender/resolver a questão.

No entanto, se Richard Rorty está certo, nenhum vocabulário é imortal. É muito mais sensato. É possível e desejável abandonar o vocabulário de onde se depreende a ideia de "homossexualidade", assim como nos recusamos a discutir sobre bruxas e bruxarias com o vocabulário da Inquisição. Esta constatação faz coro com o próprio Jurandir Freire Costa, quando da elaboração e da defesa do termo "homoerotismo" - espécie de substituto eficaz do termo em uso - por conta da maior amplidão e amplitude que oferece, quando de sua articulação a discursos críticos. 
Esta parece ser a saída mais sensata para deixar de lado o interesse por perguntas sem sentido e problemas sem solução. Na ocorrência desta situação, os atuais posicionamentos equivocados deixarão de ter espessura e sentido, assim como as crenças em feitiçaria. Serão como "um erro do tempo". Num futuro possível - e em igual medida desejável - os indivíduos de uma cidade ideal da ética humanitária e democrática serão livres para amar sexualmente de todas as formas possíveis e imagináveis. Seu limite não será o céu, mas o respeito pela integridade física e moral do outro. Heterossexuais, bissexuais e homossexuais serão apenas palavras a identificar coisas e seres que mais se parecerão com ícones em um museu. $\mathrm{Na}$ realidade, serão como os poemas de Jose de Anchieta; existirão enquanto as ondas não o apagarem.

O passeio encenado até aqui envolve uma série de referências, textos, autores e tendência teórico-críticas. De certa forma, ele busca desenhar perímetro de renovação da leitura de produção poética mais que relevante para o estudo da História da Literatura Portuguesa, num recorte comparatista, destacando a perspectiva da Estética da Recepção. Pode-se, para isso, partir do pressuposto de que a palavra-chave aqui é "leitura". Neste sentido, fazem-se pertinentes as palavras de Stephen Vizinczey, quando afirma:

Ler é um acto criativo, um contínuo exercício da imaginação que fornece carne, sentimentos, cor às palavras mortas da página; temos que ir buscar a experiência dos nossos sentidos para criar um mundo no espírito, e não podemos fazer isso sem envolver o nosso inconsciente e revelar o nosso ego. Em resumo, somos extremamente vulneráveis quando lemos, e só ficamos felizes com autores que partilhem, as nossas inclinações, preocupações, preconceitos, ilusões, pretensões, sonhos, e que tenham os mesmos valores, as mesmas atitudes em relação ao sexo, à política, à morte, etc. (VIZINCZEY, 1992, p. 244)

À parte certa tendenciosidade estilística e a radicalidade de posicionamento críticodiscursivos, a pertinência do trecho, em relação ao primado da leitura, faz-se consistente. Por outro lado, o indiciamento do prazer - a fazer lembrar Barthes - aponta para as "afinidades eletivas" que sempre exercem influências nas escolhas e no encaminhamento da(s) leitura(s) que cada leitor pode vir a fazer, como e o caso aqui. Confirma-se assim a vulnerabilidade de toda e qualquer proposta de leitura, dada sua natureza eletiva e sua índole subjetiva. Que outra perspectiva, senão esta, pode ser exemplarmente explicitada pela troca de cartas e pela produção poética, gêneros mais que subjetivos em sua "visceralidade essencial”?

A investigação que enseja o embrião deste artigo considera a obra de Alberto de Oliveira e António Nobre - incluindo aí as suas cartas - como corpus de expressão e construção de subjetividades marcadas por seu tempo, o que não é novidade. Mas as marcas a que me refiro, muitas vezes, não chegam a fazer parte do processo, como no caso da incineração das cartas de Alberto de Oliveira, até prova em contrário. 
A leitura da correspondência entre os dois autores, como instrumento de abordagem da recepção literária de sua poesia, pode sustentar hipóteses as mais variadas. Do ponto de vista da constituição de uma fortuna crítica consistente e instigante, esta correspondência é instrumento valioso para uma hermenêutica do final do século XIX em Portugal. Ambos os escritores tiveram participação ativa em eventos e publicações de sua época, produção esta que muito contribui para o desenho do quadro finissecular da Literatura Portuguesa que pode ser tomado como antessala do seu Modernismo. Foi esta a direção primacial deste artigo: a amizade literária como instrumento de abordagem hermenêutica de uma produção poética. Tal pressuposto aponta para o primado do leitor, no bojo do processo de constituição de sentido:

A estética da recepção parece (...), a tentativa mais inovadora para constituir uma sociologia da literatura não-marxista, para, de um só golpe, renovar, reanimar, deslocar a história literária. Retraçar as leituras sucessivas de uma obra por várias gerações críticas não é constituir um monte de tolices, mas destacar a dialética do livro e da leitura coletiva e revelar aspectos sempre novos de um autor, de um mito, de uma palavra. (TADIÉ, 1992, p. 192)

Considerando a produção epistolográfica entre Alberto de Oliveira e António Nobre como o locus discursivo no qual a produção poética de ambos se espraia implicitamente, na troca de impressões que retroalimenta a amizade que une os dois poetas, o estudo desta "memória individual" partilhada pode sustentar a presente hipótese de leitura: a influência da amizade o desenvolvimento da poética de ambos, por um lado; e, por outro, o caminho contrário, a correspondência como exercício do afeto que acaba por sustentar a produção poética, sobretudo se considerada a amizade no influxo do já referido pacto homossocial.

Entendo que a correspondência entre os dois poetas pode deixar transparecer uma espécie de jogo discursivo que acaba por fazer com que o missivista procure, mesmo que inconscientemente, chamar sobre si a atenção de seu interlocutor sem, no entanto, ter a prerrogativa da transparência do discurso: ele necessita de uma "resposta", na verdade, pede por ela. Ainda que a inexistência das cartas de Alberto de Oliveira, por decisão do próprio autor, seja aparentemente "uma pedra no meio do caminho". Tal situação dialoga de forma evidente com o conceito de "pacto referencial" apresentado por Lejeune, em O pacto autobiográfico, como sendo uma espécie de contrato da memória com a verdade, esta sempre reduzida à esfera das possibilidades, levando-se em consideração a série de rasuras, deformações e imprecisões às quais está submetido aquele que escreve as cartas.

Da mesma forma, em Lete: arte e crítica do esquecimento, Weinrich comenta acerca do descrédito a que Platão lança o "sistema gráfico", matéria-prima das cartas, quando afirma que a memória definha na medida em que o tempo passa e fragiliza as "certezas" que esta mesma memória consolida. Tal definhamento pode ser sanado com a releitura das cartas em articulação 
com a poesia produzida por ambos os autores portugueses, como proposto aqui. Considerando, ainda, as missivas como campo de tensões que estimulam a colisão de perspectivas distintas sobre a dominante literária da época, torna-se necessário, como contraponto da correspondência - esse camarote da criação literária, o projetado espaço para treino da escrita poética -, a sua articulação com a poesia de ambos os poetas, na perspectiva aqui adotada. Tais cartas funcionam como uma espécie de laboratório de criação poética, no âmbito da leitura, mesmo que não tenha sido esta a "intenção" dos dois.

Se a amizade é laço afetivo que pode unir pessoas independentemente de uma explicação racional, a perspectiva dos estudos de gênero pode especular sobre liames mais implícitos que a moralidade de uma época ou mesmo os princípios dormentes que, na organização social, tendem a ser recalcados, limitados e, por vezes, dissimulados. O que Sedgwick pressupõe é que haja um investimento afetivo - do naipe daqueles descritos por Freud em sua saga intelectual - nas relações entre sujeitos de mesmo sexo (daí a importância do prefixo "homo"), objetos de eleição de muitos escritos sejam poéticos ou narrativos. Longe de circunscrever um perímetro de elucubrações que seja reduzido ao exame de "preferências" e ou práticas, da ordem do sexual, o conceito por ela cunhado - homossociabilidade, ou mesmo, pacto homossocial - respalda o olhar inquisitivo do leitor que passeia por índices escritos desse desejo que se faz palavra. É, a meu ver, a hipótese de fundo que parece sustentar Jurandir Freire Costa, como aqui demonstrado.

Dito de outra forma, pouco importa as preferências sexuais dos autores dos textos que se colocam em epígrafe. Desinteressante se faz, por consequência, defender esta ou aquela justificativa para os chistes linguísticos que a literatura agencia no/pelo texto que o poeta escreve. De todas as possibilidades, o texto da carta pode ser tomado como exemplo mais afeito a esse tipo de análise/observação, dado que o autor dela fala de si, ainda que na superfície da letra a mensagem se reduza, aparentemente - e apenas assim -, ao comunicado de conteúdo diverso, de informação útil (ou não!) de referência “objetiva”.

Neste sentido, analisar um trecho de carta, como foi aqui a pedra de toque do artigo, numa articulação - via leitura atenta e verticalizada - com os poemas de ambos, é atitude que se explicita na constituição de um corpus de investigação mais plausível. A orientação desta investigação, portanto, coloca-se muito além de moralismos e/ou respeitos que possam agilizar assertivas redutoras que procuram impedir que o olhar do leitor atento encontre, nas linhas pelas quais caminha, os índices da afeição partilhada, seja pelas cartas, seja pelos poemas. Desta forma, a afetividade que alimenta a amizade de ambos não deixa de ser o eixo da referida homossociabilidade, ou, por outra, a leitura que deste material se pode fazer leva à certeza de 
que um pacto homossocial foi estabelecido prévia e, até, inconscientemente, pelos autores das cartas e dos poemas. Cabe ao leitor atento aceitar esses índices, examiná-los à luz de sua evidência e dinamizá-los na hermenêutica possível dos textos nos quais e pelos quais se explicita.

Fica, então, a título de corroboração do que aqui se propõe, o conjunto de "insinuações" - o sentido deste termo aqui não carrega nenhuma intenção pejorativa e/ou condenatória - feitas por Mario Cláudio que, de maneira um tanto apressada, são rechaçadas por Vasco de Castro em texto que "comenta" a publicação da Fotobiografia de António Nobre. Nesta, ao que parece, Mário Cláudio teria percebido alguns destes índices. A última frase do referido "comentário""Vou lavar-me as mãos" -, aponta ambiguamente para uma atitude de desprezo que muito bem pode encerrar sentido mais profundo, aquele dinamizado por preconceito, revestido de recalcamento gratuito.

Em igual medida, pode-se concluir que o discurso do mesmo comentário aponta para alguma coisa como "não vou tocar nesse assunto delicado pra não "me sujar' com isso". Constatação plausível e, em igual medida, instigante. A investigação que ora se propõe poderá também, acredito, desfazer esta dúvida. Complemente-se que o próprio Mário Claudio publicou um livro de contos, Triunfo do amor português, do qual faz parte uma narrativa intitulada “António Nobre e Alberto de Oliveira”. Na perspectiva que se desenha a partir dos comentários feitos à "Fotobiografia", parece pertinente articular a leitura das cartas em diálogo com a ficção de Mário Cláudio como já foi feito em outro artigo que aguarda sua publicação. Mais uma vez, desta forma, reitera-se o caráter comparatista da investigação (e de seus resultados), bem como reinvestindo nos pressupostos estabelecidos a partir da leitura dos trabalhos de Eve Kosofsky Sedgwick e Jurandir Freire Costa, conforme já referido anteriormente.

Considerados o conjunto de referências teóricas e metodológicas acima, e operacionalizando seus princípios à releitura das cartas de António Nobre, a investigação cria as condições para proceder à análise comparativa da correspondência. $\mathrm{O}$ trabalho, sempre em curso, não vai ser paralisado para a consideração da proposta eletiva deste artigo: estudar a correspondência como instrumento de construção, consolidação e explicitação da amizade literária de que são sujeitos os dois poetas portugueses. Para tanto, a minha proposta foi abordar este "processo" escrito a partir das ideias de Eve Kosofsy Sedgwick, sobretudo a partir de suas propostas exaradas em dois volumes: Epistemology of the closet e Between men: English literature and male homosocial desire. Ambos os livros são acompanhados de instigante estudo realizado por Jurandir Freire Costa, A inocência e o vício. Este polo teórico-metodológico orienta o desenvolvimento da abordagem da leitura da correspondência entre os poetas 
portugueses, a partir da possibilidade de se entender a amizade dos dois como exercício poético de um pacto homossocial, nos termos em que essa conceituação é apresentada, inicialmente, pelos volumes acima citados. Tal abordagem vai ao encontro do diálogo que se estabelece com o texto de Mário Cláudio, igualmente referido alhures. $\mathrm{O}$ trabalho investigativo, articulado às análises realizadas - das cartas, dos textos de referência e a fortuna crítica dos dois poetas resultará em material interessante e sedutor. Esta sedução implica em satisfação possível. Caberá ao tempo, o que tudo muda, a decisão de corroborar ou não tanto a busca, quanto a satisfação desse desejo.

\section{Referências}

AMBRIÈRE, Madeleine; CHOTARD, Loïc (orgs.). Nouvelles approches de l'épistolaire: lettres d'artistes, archives et correspondances. Actes du Colloque international tenu en Sorbonne les 3 et 4 décembre 1993.

ANGELIDES, Sophia. Carta e Literatura: correspondência entre Tchekhov e Gorki. São Paulo: Editora da Universidade de São Paulo, 2001.

ARNAUT, Ana Paula. Retrato de Rapaz (Mário Cláudio): o fascínio pela (nova) gramática da biografia. Estudos Portugueses, $\mathrm{n}^{\circ}$ 10, Recife: Associação de Estudos Portugueses Jordão Emerenciano. No prelo.

BARTHES, Roland. O prazer do texto. Trad. de Jacob Guinsburg. São Paulo: Perspectiva, 1987. Coleção Elos.

CARVALHAL, Tânia Franco; COUTINHO, Eduardo F. (orgs.). Literatura Comparada: textos fundadores. Rio de Janeiro: Rocco, 1994

CASTILHO, Guilherme de. António Nobre: correspondência. Lisboa: Imprensa Nacional-Casa da moeda, 1982.

CHARTIER, Roger (dir.) La correspondance: les usages de la lettre au XIXe siècles. Paris: Fayard, 1991.

CIRLOT, Juan-Eduardo. Diccionario de símbolos. 3 ed. Barcelona: Editorial Labor, 1994.

CLÁUDIO, Mário. Retrato de rapaz. Lisboa: Dom Quixote, 2014.

. Fotobiografia de António Nobre. Lisboa: Leya, 2007.

. Páginas nobrianas. Porto: dições Caixotim, 2004.

COSTA, Jurandir Freire. A Inocência e o vício: estudos sobre o homoerotismo. 2 ed. Rio de Janeiro: Relume-Dumará, 1992. 
. A ética e o espelho da cultura. Rio de Janeiro: Rocco, 1994.

COSTE, Didier. Trois conceptions du lecteur et leur contribution à une théorie du texte littéraire. Poétique. Paris: Seuil, n. 43, 1980.

FOUCAULT, Michel. A escrita de si. In: O que é um autor?. Trad. de Antônio Fernando Cascais e Eduardo Cordeiro. s/l: Vega, 1997, pp.129-160.

FREUD, Sigmund, Uma recordação de infância de Leonardo da Vinci. Trad. Maria João Pereira. Lisboa: Relógio D’Água, 1990.

1976, v. 12.

Recordar, repetir, elaborar. Edição Standard Brasileira. Rio de Janeiro: Imago,

GRASSI, Marie-Claire. Lire l'épistolaire. Paris: Dunod, 1998.

ISER, Wolfgang. O ato da leitura: uma teoria do efeito estético. São Paulo: Editora 34, 1996, $2 \mathrm{v}$.

JAUSS, Hans Robert. Pour une esthetique de la reception. Paris: Gallimard, 1990.

JOUVE, Vincent. A Leitura. São Paulo: Editora Unesp, 2002.

KRAMER, Heirich; SPRENGER, James. 3 ed. O martelo das feiticeiras - Maleus Maleficarum. Rio de Janeiro: Rosa dos Tempos, 1991.

LEJEUNE, Philippe. O pacto autobiográfico. Belo Horizonte: Ed. UFMG, 2008.

REID, Martine. Écriture intime et destinataire. ZFSL, v. XVIII, 1990, p. 20-26.

RICOEUR, Paul. A memória, a história, o esquecimento. Campinas, SP: Ed. Unicamp, 2008. ROCHA, Andrée Crabbé. A epistolografia em Portugal. Coimbra: Livraria Almedina, 1965.

ROSSET, Clément. L'écriture épistolaire. Nouvelle revue française. Paris, n. 329, 1980, p. 8998.

SEDGWICK, Eve Kosofsky. Epistemology of the closet. Berkeley: Los Angeles: California University Press, 1990.

. Between Men: English Literature and Male Homosocial Desire. New York: Columbia University Press, 1985.

TIN, Emerson (org.) A arte de escrever cartas: Anônimo de Bolonha, Erasmo de Rotterdam, Justo Lípsio. Campinas, SP: Editora da UNICAMP, 2005.

TINOCO, Robson Coelho. Leitor real e teoria da recepção. São Paulo: Horizonte, 2010.

VIZINCZEY, Stephen. Verdade e mentira na literatura. Trad. de Maria José Marques Figueiredo. Lisboa: Presença, 1992. 
WIER, Jean. De 1'Imposture des Diables. Paris: Coleção Analectes, 1970 (edição não comercial)

ZILBERMAN, Regina. Estética da recepção e história literária. São Paulo: Ática, 1989. 